\section{Andy Hinder}

is the CEO of digital

communication agency

STEEL London. With 25

years' experience, Hinder has

undertaken practically every

agency role, including strategic

planning, design, art direction,

copywriting, account management

and studio management. Since

being appointed to the STEEL

board in 1992, he has turned his

talents to high-level strategic

direction, acquiring and growing

such accounts as Debenhams

(which STEEL launched online in

1998), AOL, TalkTalk, Ladbrokes,

Greggs and Mark Warner. Having acquired the business (with three other partners) in 2005, he has helped to steer the agency from a heavily resourced, productionbased model, to a leaner,

forward-looking, strategically led digital agency that is firmly focused on consumer social value and the rapid employment of new technology and trends.

Keywords: Greggs, retail, sales promotion, social media, digital marketing

\section{Local and national growth}

\section{Product launch with budget constraints}

\section{Andy Hinder}

CEO, STEEL

521-525 Old York Road, Wandsworth

London, SW18 1TG, UK

Tel: +44 (0)208871 2656

Email: andy.hinder@steellondon.com

\section{Case Study}

\section{Greggs - Superstar Doughnuts prove the sales power of social networks}

\author{
Andy Hinder \\ Date Received (in revised form): 29th June, 2012
}

\begin{abstract}
Gaining awareness of a new product usually requires a large advertising budget. In its absence, Greggs used social media to generate engagement with a set of characters created for a new doughnut range. By encouraging engagement with specific flavours as part of an award voting programme - incentivized with a product trial voucher - the baked goods chain was able to post record sales during a difficult trading year.

Journal of Direct, Data and Digital Marketing Practice (2012) 14, 143-148. doi:10.1057/dddmp.2012.30
\end{abstract}

\section{Background}

Greggs is the UK's largest food brand, with more shops than McDonald's, Costa or Subway. It started out over 70 years ago with one man delivering yeast and eggs to local families so they could bake their own bread. In 1951, the first shop was opened with a bakery at the rear, allowing Greggs to bake high-quality bread, using flour milled from specially selected wheat for a distinctive taste and texture.

From the 1960s, Greggs began to grow by acquiring regional bakery retailers across the UK. Despite strong competition from supermarkets entering the bakery market, today Greggs has nearly 1,600 shops serving six million customers each week — with plans to open 600 new shops over the next few years. This has been achieved by continuous focus on Greggs' strengths: developing fresh, quality foodon-the-go at great value prices, rooted in local communities despite being a national business.

During the challenging trading conditions of 2011, Greggs achieved record sales of $£ 701 \mathrm{~m}$, a rise of 5.8 per cent, with pre-tax profit (before exceptional items) rising 1.1 per cent to $£ 53.1 \mathrm{~m}$.

\section{The problem}

Greggs was launching a new product in its high-street shops - a range of flavoured doughnuts. Within a tough economic climate, rising food 


\section{Word of mouth}

\section{Delivering social entertainment}

prices and an increasingly crowded and competitive marketplace, Greggs needed to promote the launch and drive awareness of the product.

As a consequence of tough trading conditions, Greggs' wider marketing had been tactical rather than brand-building over the previous year and the same would be true for this campaign. Only a small marketing budget would be available, so advertising in the traditional sense was not an option.

\section{The objective}

- To maximize awareness and drive sales of the flavoured doughnuts range - the average Greggs customer visits stores an average of two or three times a week, spending between $£ 2.20$ and $£ 2.30$ a time.

- To generate word of mouth and spread the message naturally. This would require mobilizing a passionate army of Greggs' supporters. (The brand's digital marketing agency, STEEL, had helped to grow Greggs' Facebook fan base from 40,000 to 280,000 in the previous 12 months and the Twitter following from 2,400 to 5,000 in the previous 9 months).

\section{The strategy}

The strategy was based on generating product advocacy and earned media. Social media was deemed to be the ideal platform to achieve this, particularly factoring in budgetary considerations. Furthermore, this was the first time Greggs had ever commissioned a digital advertising campaign to support a product launch. Working with its agency, the brand wanted to build a meaningful connection between the new products and the audience, something that would resonate far more than a traditional advertising approach.

The central idea was to 'bring the products to life' across Facebook, Twitter and YouTube to help mobilize Greggs' passionate army of supporters. This was not just about raising awareness about the range, it was also about wanting to entertain and involve people.

Providing entertainment and conversation is more conducive to helping consumers naturally spread product and brand awareness among their social circles. We wanted to deliver a rich social experience that invited participation, in line with the increasing trends in people's digital behaviour. The campaign strategy was not about advertising — it was about social entertainment.

As part of the awareness drive, the strategy also looked to broaden Greggs' appeal to new audiences and a younger demographic, without the need for additional expensive, traditional paid media.

The campaign was 6 weeks in the making and was live for 1 month.

\section{Creating the characters}

There were four doughnuts in the product range. Each was assigned an individual character with personalities based on popular A-list stereotypes and detailed backstories, including their jobs, hobbies and 


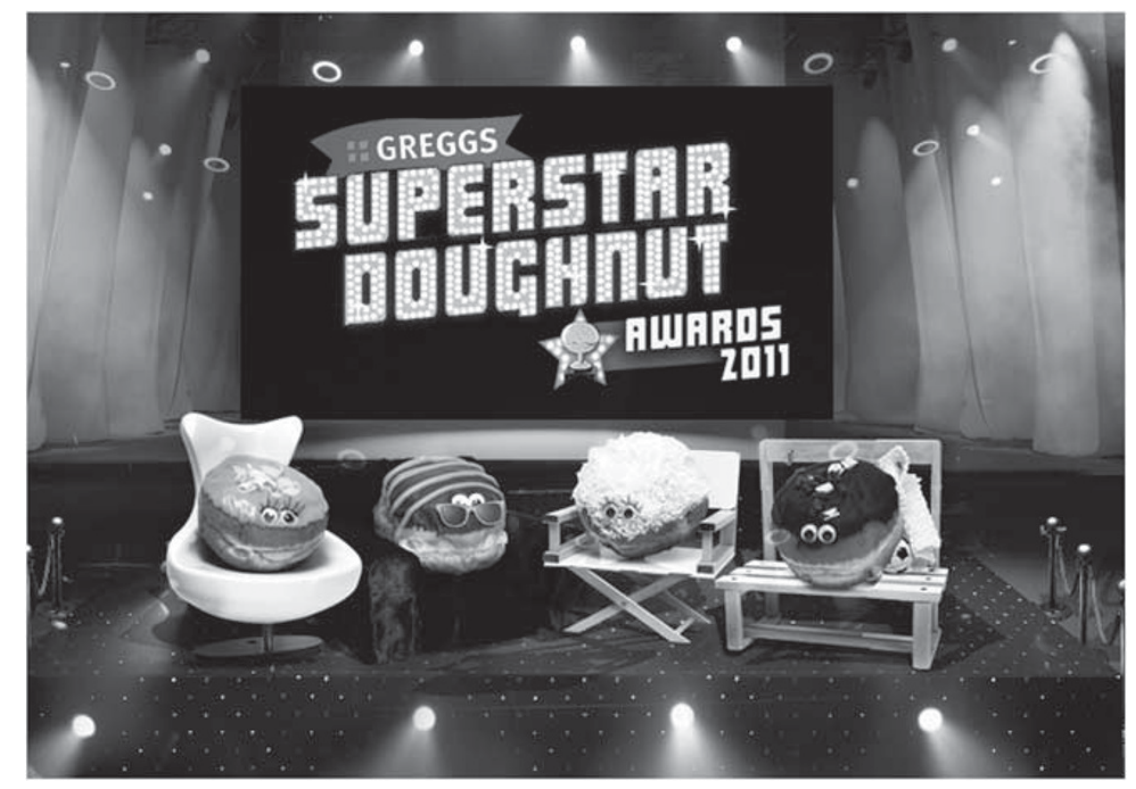

Figure 1: Superstar Doughnuts characters

past romances. Together they formed the 'Superstar Doughnuts' (see Figure 1):

- Jaffa Cake - a rockstar from America (see Figure 2);

- Strawberry Milkshake - a ditzy supermodel from Cheshire;

- Triple Choc Vanilla - a Premiership footballer from Newcastle; and

- Coconut Snowball - a Hollywood actress (see Figure 3).

A lot of effort was put into visuals and artwork. First, each doughnut was given the star treatment they deserved. From their handmade chairs and props to the animated miniature video screens, fireplaces and windows, each intricately designed set was flawlessly 'real' and perfectly to Doughnut scale. These included album covers, like 'Dark Side of the Doughnut'.

Secondly, the Doughnut World was given further depth and intrigue by creating additional scenes and stills, plus movie posters, magazine covers and newspaper articles, like the spoof magazine 'eat'. By creating this virtual Doughnut World, the doughnuts gained depth like real 'people' who consumers could talk to, get to know and have fun with.

\section{Starting the conversation - and the sales}

\section{Utilizing social media channels}

Each of the Superstar Doughnuts was brought to life on social media through YouTube, Facebook and Twitter. YouTube short videos introduced the Superstars, with the conversation continuing through their Twitter and Facebook profiles:

- YouTube: each Doughnut featured in its own video to bring it life, showing its backstory, key life moments and relationship to the other three doughnuts. The shorts also gave them a chance to use their 


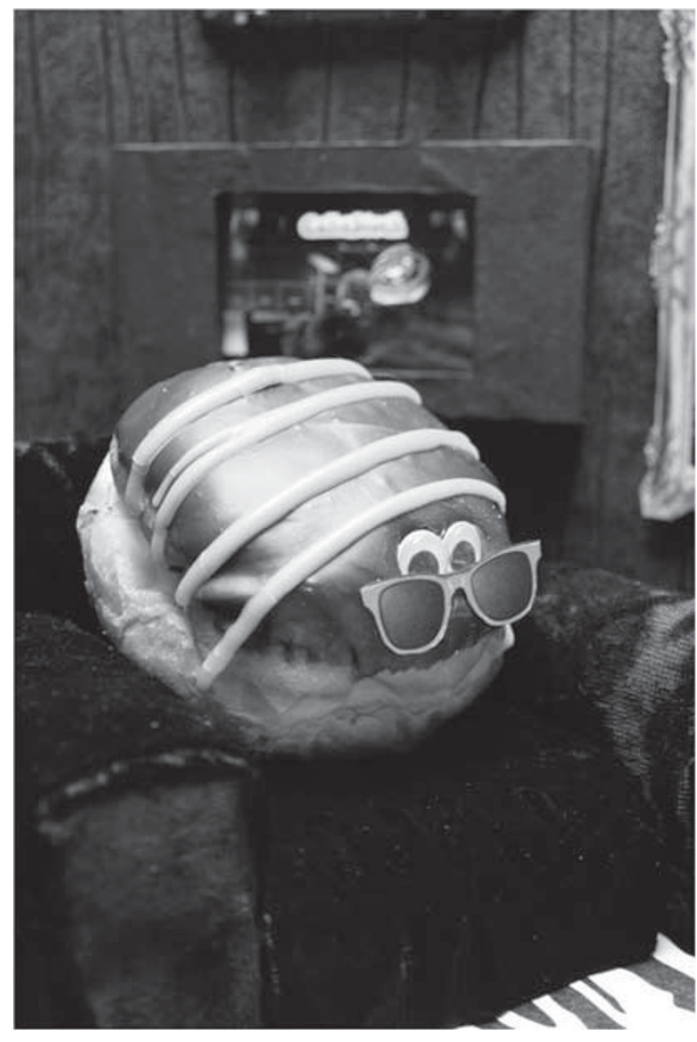

Figure 2: 'Jaffa Cake' character

catchphrases and to make an impassioned plea for votes. These videos were viewed via YouTube or the Superstar Doughnut campaign hub. Additional short videos added to the experience. Viral video seeding was also undertaken with Rubber Republic's viral network (http://www.mediafire.com/?77if2k475r67mba).

- Twitter: this channel was critical to the success of this campaign it helped bring each of the four doughnuts to life at a very personal level.

- Facebook: in addition to each doughnut having its own Facebook profile, Greggs' Facebook page released 100,000 vouchers 1 week after the campaign launch, giving the user one free doughnut from the new range with any purchase. The campaign was partly seeded through targeted Facebook advertising.

Voting and vouchers

\section{The call to action}

The key theme running through all these channels was the fight to be crowned 'Greggs Superstar Doughnut of 2011'. These awards were positioned as the Oscars of the Doughnut world - they were a BIG deal to the characters.

Consumers were encouraged to vote for their favourite Doughnut and a digital hub was created to allow consumers to do so (http:// superstardoughnuts.greggs.co.uk/). To drive voting, a 'what's in it for 


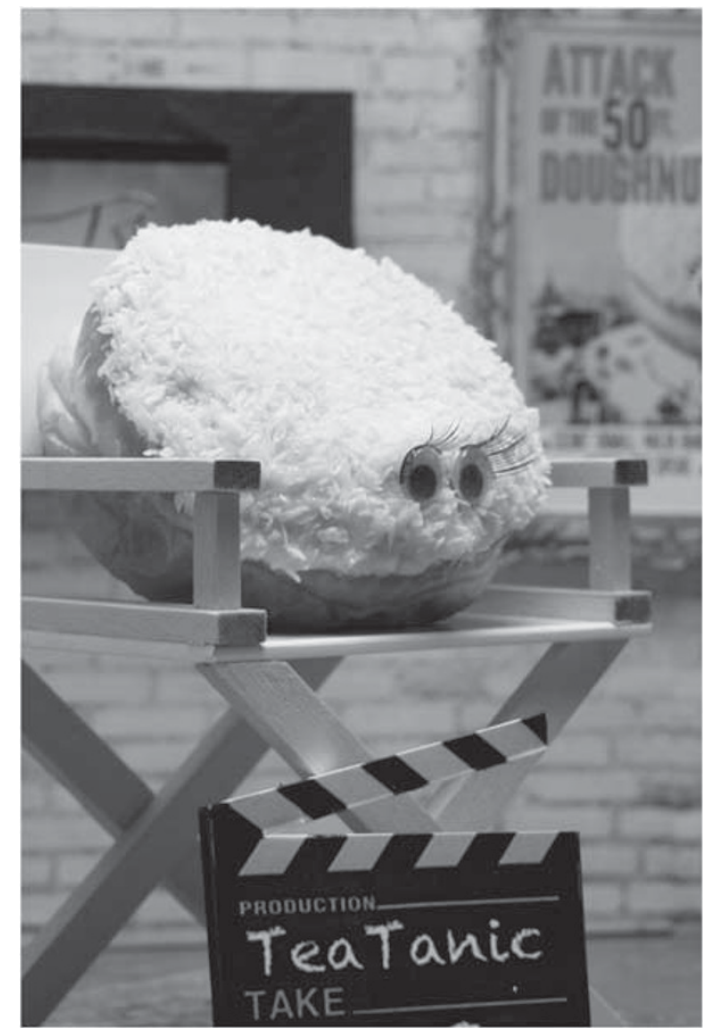

Figure 3: 'Coconut Snowball' character

me?' box was created with a free Doughnut voucher given to everyone who voted for their favourite.

These vouchers were awarded on Doughnut Day - the day the winner of the Superstar Doughnut Awards was announced - with the aim of driving footfall and related sales in-store.

\section{The results}

Thousands of brand ambassadors were galvanized into action and a very powerful earned media reach was delivered. The campaign was incredibly successful, achieving outstanding cut-through, awareness, engagement and footfall.

In just 5 weeks, 1.5 million Doughnuts were sold (circa $£ 1.3 \mathrm{~m}$ sales revenue). Greggs' CEO said this contributed to Greggs reporting a '5.4 per cent rise in total sales in its third quarter'.

Specific digital ROI in the first four weeks:

- one hundred fifty thousand web visits to Greggs.co.uk, an increase of 13 per cent month-on-month;

- thirteen million impressions across Facebook and Google Search;

- six thousand email sign-ups;

- eleven thousand new Facebook likes, double the growth of the previous month; 
- twenty plus per cent growth in views and feedback to Facebook posts;

- four thousand plus new Twitter followers and 600 conversations;

- forty-six thousand four hundred and fifty video views via YouTube and the Doughnut campaign hub;

- thousands of Doughnuts vouchers claimed;

- significant media coverage;

- one unsolicited song written by an MTV-nominated artist.

The success of the digital launch of Superstar Doughnuts has encouraged Greggs' CEO to continue focusing on tactical digital advertising. 